\title{
Collagenase inhibitor concentration in cultured cervical tissue of sheep is increased in late pregnancy
}

\author{
J. G. Raynes†, F. A. Clarke, J. C. Anderson, R. J. Fitzpatrick* and \\ H. Dobson* \\ Department of Biochemistry and Molecular Biology, Stopford Building, Manchester University, \\ Oxford Road, Manchester M13 9PT, U.K.; and *Department of Veterinary Clinical Science, \\ Neston, Wirral L64 7TE, U.K.
}

\begin{abstract}
Summary. An inhibitor of collagenase was released from cultured cervical tissue of sheep and the amounts released were greatest from tissue in late pregnancy (145-146 days). The molecular weights of material with inhibitory activity, estimated by gel filtration of extracted inhibitor, at different stages of pregnancy were different, i.e. 20000 from extracts of late-pregnant and post-partum samples and 29000 from extracts of non-pregnant samples. Inhibitor from culture supernatants had a molecular weight of 42000 . We conclude that the inhibitor has binding characteristics and molecular weights similar to those of the tissue inhibitor of metalloproteinase.
\end{abstract}

Keywords: collagenase inhibitor; cervix; pregnancy; parturition; sheep

\section{Introduction}

An increase in cervical collagenolytic activity during human pregnancy has been demonstrated using synthetic substrates and fluorescein-labelled collagen, and this increase may be involved in cervical dilatation (Kitamura et al., 1979; Uldbjerg et al., 1983). Indeed, evidence has been obtained by electron microscopy for disruption of the collagen framework at human parturition (Junquiera et al., 1980). However, electron microscopy studies of the sheep cervix have indicated that collagen fibrils remain intact although wider gaps between them become apparent during the last 2 weeks of pregnancy (Fitzpatrick, 1977; Williams et al., 1982; Aughey et al., 1983; Owiny et al., 1987). Hydroxyproline release from incubated tissue increases during pregnancy (Fitzpatrick \& Dobson, 1979) and cultured explants from the cervix of post-partum sheep secreted significantly more collagenase than did tissue taken in late pregnancy (Ellwood et al., 1981). Furthermore, collagen is more easily extracted as pregnancy progresses (von Maillot \& Zimmerman, 1976; Kleissl et al., 1978; Kitamura et al., 1979; Ito et al., 1979). The above observations indicate that collagenolytic activity plays an important part in cervical dilatation but that this activity is closely controlled.

We have examined the potential of cervical tissues from non-pregnant sheep and from ewes at various stages of pregnancy to produce collagenase and were unable to demonstrate any change in activity up to Day 146 (term is Day 147) (Raynes et al., 1988). The same observation has been made in the rat (Too et al., 1986).

Direct methods of measuring hydroxyproline release in extracts also failed to show calciumdependent collagenolytic activity (Raynes et al., 1988). These direct methods suffer from the problems that inhibitors in the tissue mask collagenase activity and that homogenization releases

$\nmid$ Present address: Department of Clinical Tropical Medicine, London School of Hygiene and Tropical Medicine, Keppel St, London WCIE 7HT, U.K. 
interfering inhibitors and proteases. When culture methods are used to demonstrate collagenase production, no enzyme activity is detectable in the first 1-2 days, and only becomes measurable at 3-5 days after the start of culture. Because behaviour of tissue explants in the first $24 \mathrm{~h}$ of culture is more likely to reflect the situation in vivo, we studied the amounts of inhibitor in the first $24 \mathrm{~h}$ of culture. To estimate inhibitor levels in tissue at various stages of pregnancy it was important that the inhibitory activity be due to tissue-derived inhibitors. We therefore characterized the inhibitor to determine whether it was similar to previously described inhibitors and to show that it was not a serum-derived inhibitor (e.g. $\alpha_{2}$-macroglobulin). We therefore determined the concentration of the inhibitor present in the cervix of sheep at different stages of pregnancy by measuring that produced by cultured tissue. The inhibitor in culture medium was compared with extracted inhibitors. This would be a direct way to determine whether the extensive changes in cervical structure before parturition could be due to a decrease in collagenase inhibitor control of collagenase action.

\section{Materials and Methods}

Materials. Cervices from non-pregnant sheep were obtained from Manchester abattoir. Cervices from pregnant ewes were obtained from pure-bred Welsh mountain sheep of known stage of pregnancy. Concanavalin A-Sepharose 4B, Sephadex G-100 and G-200 and Heparin Sepharose-4B were obtained from Pharmacia, Milton Keynes, Bucks, U.K. Dulbecco's Modified Eagles Medium (DMEM; high glucose), glutamine and sterile plastic flasks were obtained from Gibco Biocult Ltd, Paisley, U.K. Fungizone was supplied by Squibb and Sons, Hounslow, U.K. Aldrich Chemical Co. (Gillingham, U.K.) provided 4-aminophenyl mercuric acetate. Glucose oxidase test kits came from Boehringer, Lewes, East Sussex, U.K. Aprotinin, carbonic anhydrase, collagenase type 1A, cytochrome C, gentamycin sulphate, guanidine hydrochloride, Hepes ( $N$-2-hydroxyethylpiperazine- $N^{\prime}$-2-ethane sulphonic acid sodium salt), $N$-ethyl maleimide, ovalbumin, progesterone, soyabean trypsin inhibitor and trypsin were supplied by Sigma Chemicals (Poole, Dorset, U.K.). All other chemicals were supplied by BDH Chemicals (Poole, Dorset, U.K.). Collagen labelled in vivo with $\left[{ }^{14} \mathrm{C}\right]$ glycine was kindly provided by Dr D. E. Woolley (Department of Medicine, University Hospital of South Manchester).

Tissue culture. Cervical tissue was cultured on grids in $25 \mathrm{~cm}^{2}$ plastic flasks which contained DMEM ( $\left.3 \mathrm{ml}\right)$ incorporating $25 \mathrm{~mm}$-Hepes, $2 \mathrm{~mm}$-glutamine, $50 \mu \mathrm{g}$ gentamycin sulphate $/ \mathrm{ml}, 50 \mu \mathrm{g}$ fungizone $/ \mathrm{ml}$, exactly as described previously (Raynes et al., 1988). Culture viability was checked by measuring glucose in the medium (Woolley et al., 1975; Raynes et al., 1988). Some cultures were performed with added progesterone dissolved in ethanol $\left(10^{-6} \mathrm{M}^{-}\right.$ progesterone, $2 \%$ ethanol final concentration) and compared with controls containing ethanol alone.

Collagenase preparation. Collagenase was semi-purified according to Woolley et al. (1975). Tissue culture medium showing collagenase activity was pooled, concentrated by ultrafiltration (PM10) and fractionated on a Sephadex G200 column $(45 \times 2.5 \mathrm{~cm})$. The column was equilibrated and eluted at $12 \mathrm{ml} / \mathrm{h}$ with $20 \mathrm{~mm}$-Tris- $\mathrm{HCl} \mathrm{pH} 8.0$ containing $0.17 \mathrm{M}-\mathrm{NaCl}$ and $10 \mathrm{~mm}-\mathrm{CaCl}_{2}$. Those fractions containing collagenase activity were pooled and frozen in $2 \mathrm{ml}$ samples.

Collagenase and inhibitor assays. The collagenase assay was based on that of Woolley et al. (1976). Sample (25$100 \mu \mathrm{l}$ ) was diluted to $100 \mu \mathrm{l}$ with DMEM and made up to $100 \mu \mathrm{l}$ with $50 \mathrm{mM}$-Tris-HCl $\mathrm{pH} 8.0$ containing $0.17 \mathrm{M}$ $\mathrm{NaCl}$. This was added to collagen substrate $(100 \mu \mathrm{g}, 1700$ c.p.m. $37.5 \mu \mathrm{l})$ which was gelled at $37^{\circ} \mathrm{C}$ for $16 \mathrm{~h}$. Duplicate assays were incubated for $20 \mathrm{~h}$ at $37^{\circ} \mathrm{C}$ and centrifuged $(10000 \mathrm{~g}, 15 \mathrm{~min})$.

Percentage lysis was calculated from the difference between counts released by sample and blank medium divided by the difference between counts released by bacterial collagenase and blank medium. One unit of collagenase degrades $1 \mu \mathrm{g}$ collagen in $1 \mathrm{~min}$ at $37^{\circ} \mathrm{C}$. Bacterial collagenase $(20 \mu \mathrm{g}, 20 \mu \mathrm{l}, 1 \mathrm{mg} / \mathrm{ml})$ released $1700 \mathrm{c} . \mathrm{p} . \mathrm{m}$. and $10 \%$ of the total counts was released in the presence of blank medium. Trypsin blanks gave $5-10 \%$ lysis.

The inhibitor assay followed the same procedure except that $30-40 \mu$ l of the semi-purified enzyme were added to the incubation after the inhibitor sample or blank medium had been added. The assay was linear below $60-70 \%$ lysis (Fig. 1). A unit of inhibitor is defined as that amount which inactivates 2 units of collagenase by $50 \%$.

Activation of enzyme was either by addition to the assay of amino phenyl mercuric acetate ( $2 \mathrm{~mm}$ ) or prior treatment of inhibitor with $26 \mu \mathrm{l}$ of $0 \cdot 1 \mathrm{mg}$ trypsin/ml followed by an excess $(13 \mu \mathrm{l})$ of $\mathrm{l} \mathrm{mg}$ soyabean trypsin inhibitor $/ \mathrm{ml}$.

Inhibitor characterization. Culture medium (Day 1) was ultrafiltered on a PM10 membrane (Amicon Ltd), dialysed against water, freeze dried and resuspended in $25 \mathrm{~mm}$-sodium cacodylate buffer (pH 7.2) containing $10 \mathrm{~mm}$ $\mathrm{CaCl}_{2}, 0.05 \% \mathrm{Brij}-35,1 \mathrm{M}-\mathrm{NaCl}$ and $0.02 \%$ (w/v) $\mathrm{NaN}_{3}$ (Cawston et al., 1984). Insoluble material was removed by entrifugation $(2000 \mathrm{~g}, 10 \mathrm{~min})$. Inhibitor preparations were added to a $\mathrm{G}-100$ column $(80 \times 2.5 \mathrm{~cm})$ equilibrated and uted in the same buffer. Fractions $(11.5 \mathrm{ml})$ were dialysed against water, an aliquant was assayed for collagenase is hibitor, and the fractions freeze dried. The column was calibrated in the same buffer with ovalbumin $\left(M_{\mathrm{r}} 45000\right)$, $\therefore$ rbonic anhydrase $\left(M_{\mathrm{r}} 29000\right)$, cytochrome c $\left(M_{\mathrm{r}} 12400\right)$ and trasylol $\left(M_{\mathrm{r}} 6500\right)$. 


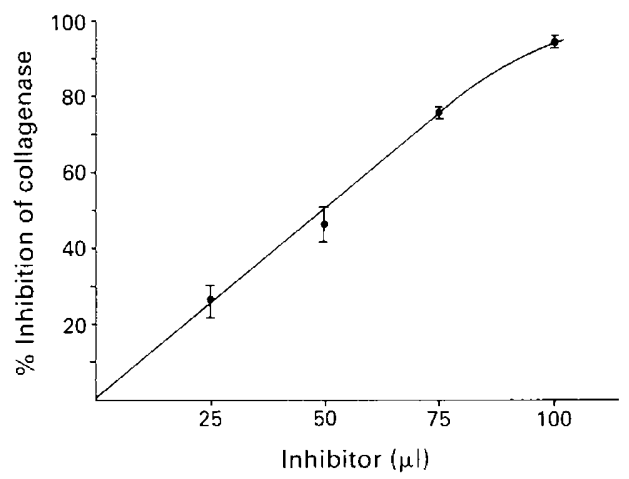

Fig. 1. Percentage inhibition of collagen substrate lysis by increasing collagenase inhibitor concentrations. Digestion of in-vivo labelled collagen $(100 \mu \mathrm{g})$ by aliquants of semi-purified collagenase was inhibited by concentrated inhibitor supernatants. Values are mean \pm s.e. of triplicate estimations.

Inhibitor, purified as above, dissolved in cacodylate buffer containing $1 \mathrm{mM}-\mathrm{MgCl}_{2}$ and $1 \mathrm{~mm}-\mathrm{MnCl}_{2}$ was loaded onto a Concanavalin A-Sepharose column $(0.9 \times 10 \mathrm{~cm})$. Adsorbed protein was eluted with buffer containing $2 \%$ (w/v) 1-0-methyl-D-glucopyranoside. Bound and unbound fractions were dialysed and assayed for inhibitor.

Inhibitor which bound to Concanavalin A-Sepharose was dialysed against cacodylate buffer containing $0.05 \%$ Brij-35 and $10 \mathrm{~mm}-\mathrm{CaCl}_{2}$ added to a heparin-Sepharose column $(0.9 \times 6 \mathrm{~cm})$ and eluted with the same buffer containing $! \mathrm{M}-\mathrm{NaCl}$. Bound and unbound fractions were dialysed against distilled water and assayed for inhibitory activity.

Extraction of inhibitor. The cervical tissue was homogenized (Orme Scientific Ltd, Manchester) in $1 \mathrm{M}$-guanidine hydrochloride $(\mathrm{GuCl}), 100 \mathrm{~mm}$-Tris- $\mathrm{HCl} \mathrm{pH} 7.5$ containing $4 \mathrm{~mm}-\mathrm{NEM}$ and $0.02 \%$ (w/v) $\mathrm{NaN}_{3}$. The extract was stirred for $12 \mathrm{~h}$ at $4^{\circ} \mathrm{C}$ and made up to approximately $4 \mathrm{M}-\mathrm{GuCl}$ with solid $\mathrm{GuCl}$ and centrifuged at $30000 \mathrm{~g}$ for $1 \mathrm{~h}$. Proteoglycans and other high molecular weight molecules were removed by ultrafiltration through a YM100 membrane (Amicon Ltd). The ultrafiltrate was dialysed against column buffer for gel filtration, as described above.

\section{Results}

All cultured tissue produced both collagenase and collagenase inhibitor. Collagenase production outstripped collagenase inhibitor production between Days 2 and 5 in culture and under these conditions became detectable (Fig. 2). In the first $24 \mathrm{~h}$, however, there was always an excess of the inhibitor and in many cultures inhibitor was in excess up to $48 \mathrm{~h}$ and active collagenase may not be detected until Day 5. Inhibitor activities typically followed the pattern shown in Fig. 3, supernatant inhibitor concentration (mean \pm s.e. of 4 replicates) remained approximately constant for up to 5 days in the presence of progesterone and in its absence decreased significantly after Day $3(P=$ 0.01 , Student's $t$ test). If inhibitor synthesis was constant from Day 1 to 5 , this suggested that serum inhibitors might not contribute greatly to the inhibitor levels in medium on Day 1 of culture. To test this hypothesis we looked for evidence for $\alpha_{2}$-macroglobulin inhibition on Day 1. Treatment of the inhibitor supernatants by ultrafiltration on a high molecular weight cut off membrane (YM100) showed that the high molecular weight fraction contained less than $20 \%$ of the inhibitory activity. When culture fluid was fractionated on gel filtration (G-100) no high molecular weight inhibitory activity was discovered (Fig. 4).

It was not possible to reverse the inhibition with trypsin or aminophenyl mercuric acetate: $0 \cdot 725$ inhibitor units of activity in the medium was only marginally altered ( 0.6 units) after treatment with aminophenyl mercuric acetate or trypsin (to 0.65 units).

To investigate the major inhibitor present, medium from the first 2 days of culture, shown to have inhibitory activity, was concentrated and separated on a G-100 Sephadex column. The inhibitor activity had a molecular weight of 42000 by this method (Fig. 4). The inhibitory activity which 


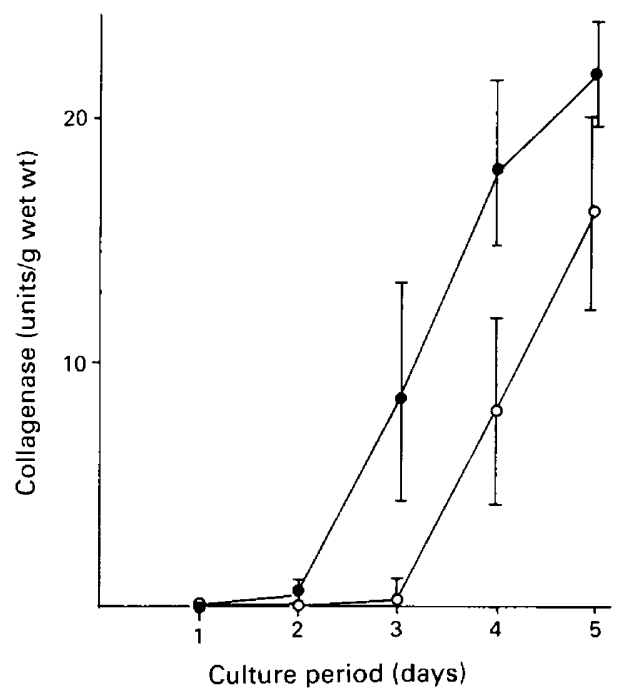

Fig. 2. Collagenase production in medium during the first 5 days of culture of sheep cervical tissue. Collagenase activity (latent + active collagenase - ; active collagenase, $\bigcirc-O$ ) in supernatants was assayed by release of radioactive peptides from labelled collagen gels. Values are mean \pm s.d. of 8 determinations.

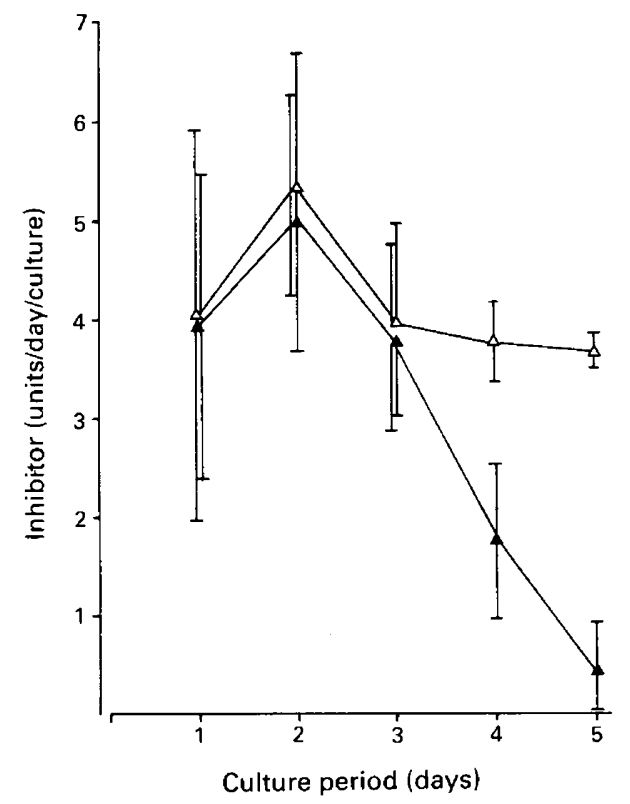

Fig. 3. Collagenase inhibitor production in culture medium over 5 days. Triplicate determinations were performed on culture supernatants from tissues incubated with $(\triangle-\Delta)$ and without $(\boldsymbol{\Delta}-\boldsymbol{\Delta})$ progesterone $\left(10^{-6} \mathrm{M}\right)$. Results are mean \pm s.e. 


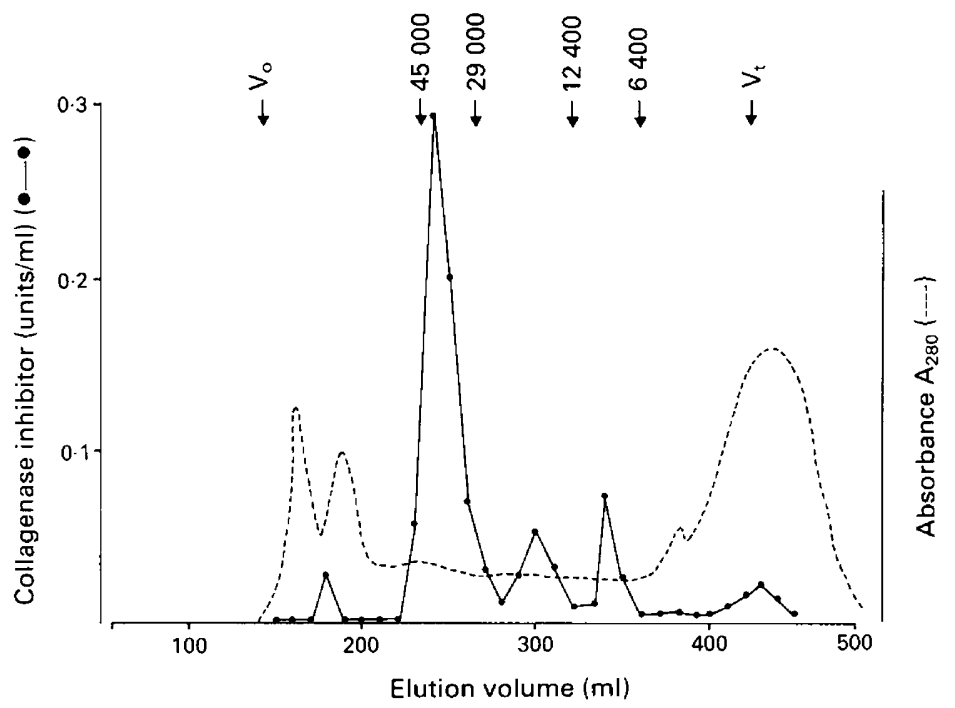

Fig. 4. Gel filtration of inhibitory activity in concentrated medium from cultures of sheep cervical tissue. Concentrated culture medium $(5 \mathrm{ml})$ was applied to Sephadex G-100. Molecular weight markers are indicated.

could be extracted from cervices of non-pregnant sheep had a lower molecular weight of about 29000 but a substance with an even lower molecular weight was found as the main inhibitory peak in extracts from late-pregnant and post-partum sheep (Fig. 5). It was not possible to reverse the inhibition of any of these peaks with aminophenyl mercuric acetate (results not shown). There was evidence for material of molecular weight 42000 in the extracts as well as a higher molecular weight inhibitor but these were of lower activity (Fig. 5). In the culture supernatants there was some evidence for inhibitors of lower molecular weight, of about 20000 and 10000 but these were also of low activity (Fig. 4).

About $60 \%$ of the activity of the inhibitor from medium, purified by gel filtration, could be bound to a Concanavalin $\mathbf{A}-$ Sepharose column. The inhibitor which bound to Concanavalin $\mathrm{A}-$ Sepharose also bound to heparin-Sepharose and $80 \%$ of the activity was eluted with $1 \mathrm{M}-\mathrm{NaCl}$ whilst $20 \%$ passed through without binding.

Collagenase inhibitor released (units $\times 10^{-4} / \mathrm{mg}$ tissue) from explants measured in duplicate for each sheep during the first $24 \mathrm{~h}$ of culture was $3.21 \pm 0.49$ for 11 non-pregnant ewes; $2.91 \pm 0.48$ for 5 ewes at $0-80$ days of pregnancy; $3.50 \pm 0.81$ for 6 ewes at $100-130$ days of pregnancy; and $3.93 \pm 0.63$ for 13 ewes at 145-146 days of pregnancy. There was no apparent difference between the inhibitor produced per $\mathrm{mg}$ tissue during the first $24 \mathrm{~h}$ of culture of explants from non-pregnant sheep, and that from ewes during Days 0-80 or Days 100-130 of pregnancy. However, there was a significantly increased inhibitory activity from the later pregnant samples, when compared to the non-pregnant or Day 0-80 groups $(P=0.005$, Student's $t$ test $)$.

\section{Discussion}

The use of ultrafiltration and gel filtration demonstrated that the inhibitor responsible for the reduction in the collagenase activity was not $\alpha_{2}$-macroglobulin. As this represents most of the inhibitory activity in serum (95\% in human serum) (Woolley et al., 1975), this implies that inhibitor in the medium was probably of tissue origin. This conclusion was supported by the ability of progesterone to cause an approximately constant rate of secretion of inhibitor for up to 5 days. 

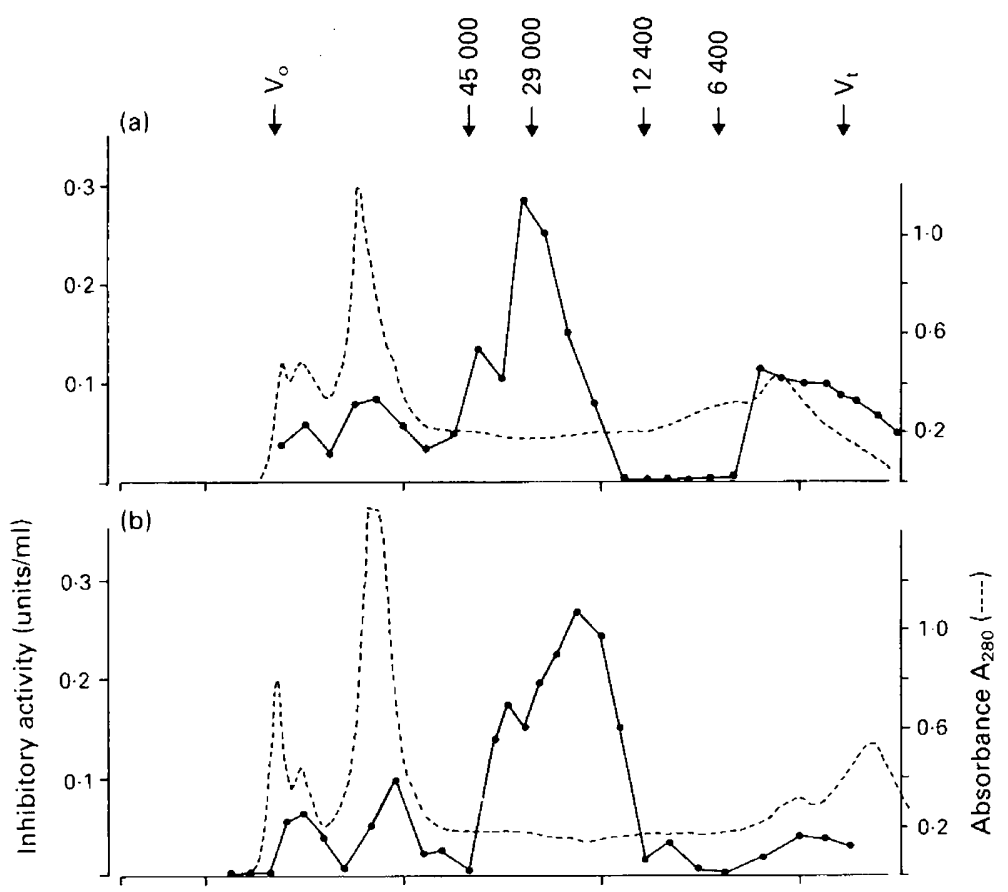

(c)

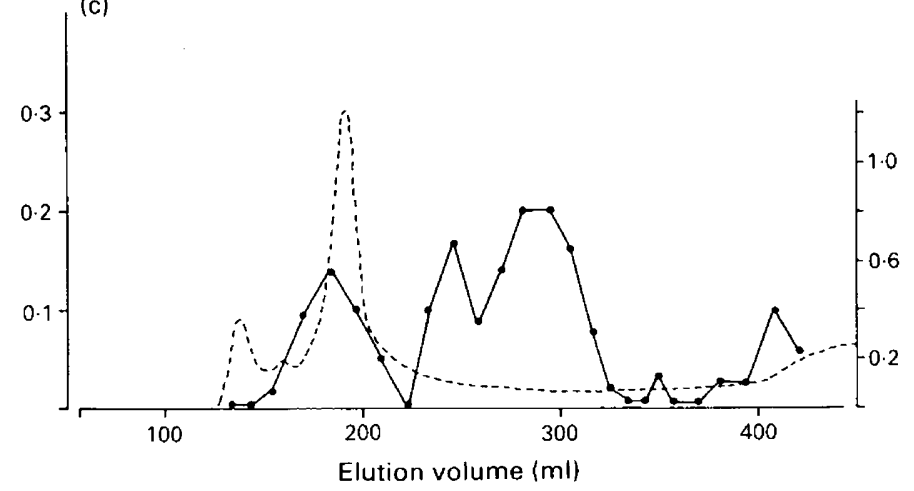

Fig. 5. Gel filtration of collagenase inhibitor in sheep cervical tissue homogenates. Homogenates of cervix from (a) non-pregnant, (b) late pregnant and (c) post-partum sheep were centrifuged, ultrafiltered and loaded onto a G-100 column. Molecular weight markers are indicated.

Progesterone has been shown to prevent synthesis of collagenase in cultures up to Day 5 previously. Due to the high molecular weight of $\alpha_{2}$-macroglobulin it is not found at extra-vascular sites.

The molecular weight of inhibitor from the extracted tissue samples was lower than that observed in the culture medium. The reason may be due to differences in glycosylation. The molecular weight of inhibitor from cultured cartilage supernatants is higher $(32000)$ than that of extracted inhibitor (22 000) (Bunning et al., 1984). An inhibitor of molecular weight 28 000-29 000 has been observed in extracts from amniotic fluid (Murphy et al., 1981), cartilage (Murray et al., 1986), and bone (Cawston et al., 1981). A substance of molecular weight 20000 has also been obtained from amniotic fluid (Bunning et al., 1984). When cultured fibroblasts were extracted (Murphy et al., 1985) an inhibitor of molecular weight 24000 was the main product but culture fluid also contained an inhibitor of molecular weight 29000 . These inhibitors were immunologically related to a precursor of molecular weight 20000 (Murphy \& Werb, 1985). It has 
been shown that interleukin-1 can stimulate production of tissue inhibitor of metalloproteinase (Murphy et al., 1985). Since ripening of the cervix has been likened to an inflammatory process and infiltration of inflammatory cells has been noted (Junqueira et al., 1980; Liggins, 1981), interleukin1 could be causing increased inhibitor secretion, although it also increases collagenase production. It may be that the lower molecular weight of inhibitor observed in late-pregnant tissues was due to an increased turnover. Inhibitor from extracted tissue was of much lower activity than that released from the same weight of explants, perhaps due to the quantity of enzyme released during tissue homogenization.

This study has shown that there is an inhibitor present in cervical tissue that is of cervical origin and appears to be similar to tissue inhibitor of metalloproteinase because it inhibits irreversibly, it has similar molecular weights, and binds to Concanavalin A and heparin (Murphy et al., 1981; Bunning et al., 1984; Murphy \& Werb, 1985). The increasing concentration of inhibitor in late pregnancy at least up to Day 146 (the day before parturition begins) does not support the hypothesis that collagenase action leads to cervical softening. The results described here cannot rule out the possibility that a transient local expression of collagenase may not be detected in tissues which are also increasing their inhibitor synthesis and secretion. However, we would suggest that a more likely method of cervical dilatation would involve synthesis of a matrix that separates the collagen fibres of the cervix and it is degradation of this interposing structure that causes the rapid softening at parturition.

We thank the Wellcome Trust for financial support, and J. Owen and D. Spiller, of the Department of Veterinary Clinical Science, University of Liverpool, for assistance in obtaining cervical samples.

\section{References}

Aughey, E., Calder, A.A., Coutts, J.R.T., Fleming, R., McManus, T.J. \& Munro, C.D. (1983) Pregnancyassociated changes in the physical and microscopic characteristics of the ovine cervix. J. Anat. 136, 389-399.

Bunning, R.A.D., Murphy, G., Kumar, S., Phillips, F. \& Reynolds, J.J. (1984) Metalloproteinase inhibitors from bovine cartilage and body fluids. Eur. $J$. Biochem. 139, 75-80.

Cawston, T.E., Galloway, A., Mercer, E., Murphy, G. \& Reynolds, J.J. (1981) Purification of rabbit bone inhibitor of collagenase. Biochem. J. 195, 159-165.

Cawston, T.E., Mercer, E., Silva, M. \& Hazleman, B.L. (1984) Metalloproteinases and collagenase inhibitors in rheumatoid synovial fluid. Arth. Rheum. 27, 285-290.

Ellwood, D.A., Anderson, A.B.M., Mitchell, M.D., Murphy, G. \& Turnbull, A.C. (1981) Prostanoids, collagenase and cervical softening in sheep. In The Cervix in Pregnancy and Labour, pp. 57-73. Eds D. A. Ellwood \& A. B. M. Anderson. Churchill Livingstone, Edinburgh.

Fitzpatrick, R. J. (1977) Dilatation of the uterine cervix. In The Fetus and Birth (Ciba Symp. No. 47), pp. 31 -47. Eds J. Knight \& M. O'Connor. Elsevier, Amsterdam.

Fitzpatrick, R.J. \& Dobson, H. (1979) The cervix of sheep and goat during parturition. Anim. Reprod. Sci. 2, 209-224.

Ito, A., Kitamura, K., Mori, Y. \& Hirakawa, S. (1979) The change in solubility of type I collagen in human uterine cervix in pregnancy at term. Biochem. Med. 21, 262-270.

Junqueira, L.C.U., Zugaib, M., Montez, G.S., Toledo, O.M.S., Kristztan, R.M. \& Shigahara, K.M. (1980) Morphologic and histochemical evidence for the occurrence of collagenolysis and for the role of neutrophilic polymorphonuclear leukocytes during cervical dilatation. Am. J. Obstet. Gynecol. 138, $237-281$.

Kitamura, K., Ito, A., Mori, Y. \& Hirakawa, S. (1979) Changes in the human uterine cervical collagenase with special reference to cervical ripening. Biochem. Med. 22, 332-338.

Kleissl, H.P., van der Rest, M., Naftolin, F., Glorieux, F.M. \& Leon, A. (1978) Collagen changes in the human uterine cervix at parturition. Am. J. Obstet. Gynecol. 130, 748-753.

Liggins, G.C. (1981) Cervical ripening as an inflammatory reaction. In The Cervix in Pregnancy and Labour, pp. 1-9. Eds D. A. Ellwood \& A. B. M. Anderson. Churchill Livingstone, Edinburgh.

Murphy, G. \& Werb, Z. (1985) Tissue inhibitor of metalloproteinases. Identification of precursor forms synthesised by human fibroblasts in culture. Biochim. Biophys. Acta 839, 214-218.

Murphy, G., Cawston, T.E. \& Reynolds, J.J. (1981) An inhibitor of collagenase from human amniotic fluid. Biochem. J. 195, 167-170.

Murphy, G., Reynolds, J.J. \& Werb, Z. (1985) Biosyntl $\epsilon$ sis of tissue inhibitor of metalloproteinases by huns, in fibroblasts in culture. J. biol. Chem. 260, 3079-308?. 
Murray, J.B., Allison, K., Sudhalter, J. \& Langer, R. (1986) Púrification and partial amino acid sequence of a bovine cartilage derived collagenase inhibitor. $J$. biol. Chem. 261, 4154-4159.

Owiny, J.R., Appleton, J., Fitzpatrick, R.J. \& Spiller, D. (1987) Scanning electron microscopy of the wall of the ovine cervix uteri in relation to tensile strength at parturition. Res. Vet. Sci. 43, 36-43.

Raynes, J.G., Anderson, J.C., Fitzpatrick, R.J. \& Dobson, H. (1988) Collagenase activity is not increased in cervical softening in the ewe. Coll. rel. Res. (in press).

Too, C.K.L., Kong, J.K., Greenwood, F.C. \& BryantGreenwood G.D. (1986) The effect of oestrogen and relaxin on uterine and cervical enzymes: collagenase, proteoglycanase and $\beta$-glucuronidase. Acta endocr. Copenh. 111, 394-403.

Uldbjerg, N., Ulmsten, U. \& Ekman, G. (1983) The ripening of the human uterine cervix in terms of con- nective tissue biochemistry. Clin. Obstet. Gynecol. 26, 14-26.

Von Maillot, K. \& Zimmerman, B.K. (1976) The solubility of collagen of the uterine cervix during pregnancy and parturition. Arch. Gynaekol. 220, 275-280.

Williams, L.M., Hollingsworth, M. \& Dixon, J.S. (1982) Changes in the tensile properties and fine structure of the rat cervix in late pregnancy and during parturition. J. Reprod. Fert. 66, 203-211.

Woolley, D.E., Glanville, R.W., Crossley, M.J. \& Evanson, J.M. (1975) Purification of rheumatoid synovial collagenase and its action on soluble and insoluble collagen. Eur. J. Biochem. 54, 611-622.

Woolley, D.E., Roberts, D.R. \& Evanson, J.M. (1976) Small molecular weight $\beta-1$ serum protein which specifically inhibits human collagenases. Nature, Lond. 261, 325-327.

Received 14 January 1988 